\title{
11 Solidarity and tension across generations in welfare democracies
}

\author{
Asgeir Falch-Eriksen
}

\section{Introduction}

As both a distinct and interconnected depiction of modern social life, social generation has never become a lasting branch of theoretical discussion. Classic contributions are notably frequently referenced, especially Karl Mannheim's seminal essay "On the Problem of Generations", published first in 1928 (Mannheim, 1952). Other contributors, such as Talcott Parsons, Shmuel Eisenstadt, or Norbert Elias, have also contributed to the sociology of generation and have embedded their contributions into their more significant social scientific contributions. Nevertheless, relatively recent publications show promise in developing the concept of generation further, such as Aboim and Vasconcelos, who embed their contributions in Foucault's scholarly tradition. They argue for a concept of generation as a product of "discourses of difference" rather than Mannheimian "generational units" as the dominant force of social change (2014). Purhonen utilises the scholarly tradition of Bourdieu to argue against the unhealthy usage of ascriptive generations, so-called generationalism, to claim generational shifts where there are none (Purhonen, 2016). I would thereby argue the call remains for attempting to build more elaborate theoretical accounts on the sociology of generation, contributing to a richer conceptual framework to provide a more accurate explanation.

Empirical research on generation nevertheless abounds, and it makes no sense referencing the lot here. The variation is broad, from studying welfare states' impact on different concurrent generations; how politics affects specific generations worse than others; how distinct generations build solidarity and change while others remain complacent and harvest the fruits of social cooperation and stability; how cultural types such as Boomers, 68-generation, and Millennials are brackets of birth cohorts carrying a normative insignia, what Mannheim referred to as entelechies, identifying who they are and what social change they stood for; and how family generation, lineage, kin, local community, and coping through life-courses is affected by the social change are the tip of the iceberg of examples on research topics that draw on a concept of generation one way or the other. However, a common denominator is a reliance on rather general and unspecified concepts of generation or conceptual oversimplifications, such as mere birth cohorts or mothers. While doing so is perfectly fine, it nevertheless does not do 
justice to generations' role as socially embedded groups (Aboim \& Vasconcelos, 2014; Bristow, 2016; Pilcher, 1994). This chapter, however, is overburdened as a theoretical contribution and will start broadly with a concept of social generations as a birth cohort embedded into the social order, and in this sense have the same point of departure as Mannheim (1952) and Eisenstadt (1971), and others (See Bristow, 2016). The social order that generations are embedded into will be treated as conflict-free networks of individuals who interact collectively to solve problems and coordinate action, which abides by known action norms with corresponding generalised behavioural expectations.

The normative composition of order, and the character of what brings individuals together across generations, depends on the underlying mechanisms of social order. Through time, the normative composition of order should be expected to fluctuate and change character as new generations arrive. Hence, although order prevails across generations and contains a normative composition of solidarity that is basic to order itself, new generations feed into order and contribute to shaping another, dubbed as more current and ongoing solidarity. Social generations, then, carry with them a specific solidarity. The social order, then, consists first of mechanisms of interaction that can establish order, while secondly and simultaneously producing a specific type of normativity that participating individuals subscribe to in a solidaristic fashion. Third, with concurrent social generations, birth cohorts carry with them interests and needs specific to each cohort and where in the course of life they are.

This chapter will borrow from Eisenstadt's "From Generation to Generation" (1971) and how he leans into the functionalist approach of Talcott Parsons. Eisenstadt seeks to explain social generations' role as a modern phenomenon and a challenge to social order (Eisenstadt, 1971). He aims to describe the prevalence of social order, its stability, provided concurrent birth cohorts and the tensions and conflicts they bring with them that need to be resolved to secure social order through time. Correspondingly, a traditional concept of generation, as kinships, is in this sense inadequate to capture the complexity of social interaction through the life-course embedded in complex social systems, whereas birth cohorts become more manageable. Furthermore, kinship-like approaches to generation analysis do not become sufficiently accurate to explain social changes throughout the events affecting persons throughout their life-courses and how generations continuously contribute to social order within modern complex societies. This is even more apparent provided the rate and pace of social change, and how it affects large population groups of birth cohorts and how birth cohorts affect both social change and the political-normative composition of the welfare state all the time (Eisenstadt, 1971; Giddens, 1991).

In this chapter, by first using Eisenstadt as a stepping stone, we will understand social generation as a normative-political and sociological concept in combination, which can be used to explain social order and the development of a political order through democratic self-government. Hence, each social generation is not only partaking in their own lives but also participating according to a civic republican ethos in collective decision-making and coordination. Through 
this effort, each generation also becomes authors of legislation, regulation, and administrative implementation of welfare state policies and programmes. The generation concept must be able to explain the prevalence of social order and the legal order of a welfare state and how welfare programmes and policies are transferred across generations with seemingly slow-moving changes. We will first elaborate on the context provided by modernity and what implications complexity plays. Second, we will lay out the motivation for establishing order. We will draw on what Parsons referred to as the "Hobbesian problem of order" to explain how motivation towards order cannot be reduced to rational self-interest but will need a concept of mutual understanding. Third, we will draw on the motivational force to establishing order and explain how social order is also a normative expression of a sense of morality, which will be referred to as solidarity. Fourth, we will elaborate on how a concept of solidarity becomes transformed through democratic law-making to a welfare state, and how we must speak of social solidarity as embedded in a fluctuating social order, and a version of it embedded in the welfare state as political solidarity. Fifth and last, we will introduce tensions and change within the order and how that shapes and reshapes solidarity.

\section{Social generation as a modern concept}

The first step is to extrapolate a concept of "social generation" that can explain social change within modern and complex societies, such as the advanced welfare states. Complexity is predominantly caused by processes of modernity, such as system differentiation, increased division of labour, pluralism of lifestyles, and so on (Giddens, 1991; McCarthy, 1985). This claim on increased complexity has only increased in strength (Habermas, 1988, 2015). That social generation is a modern concept was a point was stressed by Eisenstadt explicitly but is also represented in Mannheim's elaboration on the sociology of generation. Eisenstadt referred to social generations in non-kinship societies, a dubious term he used to denote modern societies. He argued that modern industrialised social orders with a highly differentiated workforce, and with active governments solving collective problems of decision-making and coordination, allocate roles where citizens interact with no "regard to the familial, kinship, lineage, ethnic or hierarchical properties of those individuals" (Eisenstadt, 1971). Generation, conceptually, takes on a new form and new type of relevancy for understanding modern social orders, one that is detached from kinship roles. It focuses instead on individual life-courses and how they are embedded in social reality, on the one hand, and how politics affect individuals in their capacity as generations, on the other. $\mathrm{He}$ continues to connect modern interaction to generalised rules of expectations on a systemic societal level rather than fixed on roles and shared meaning. Carrying membership within the social order itself, operationalised as citizenships, is distributed to all and does not depend on the descent. Also, citizenships and groups of citizens become autonomous groups interconnected to collective decision-making and coordination and become the object of political allocation (Eisenstadt, 1971). 
The kinship model is still relevant within the modern society, but on a microlevel, describing the familiar "taken-for-granted" context of each individual, that is, their lifeworlds, and where interpersonal relations characteristically presuppose a shared moral approval as the basis for intersubjective understanding. A modern individual's lifeworld "reproduces itself only through ongoing communicative actions ... [the] lifeworld embraces us as an unmediated certainty, out of whose immediate proximity we live and speak" (Habermas 1996a:23).

Kinship is predominantly an unavoidable fact of human life and alludes to local social networks where each person is embedded. Kinships, however, are characterised by behavioural expectations that are not justified from one local kinship system to the next. Social interaction thereby has a local fusion of what is normatively permissible and what is acted upon that is not compatible with modern stable social interaction across kinships in a wider social system. For interaction to be stable within societies consisting of kinships, and even families, what is deemed permissible action from a normative perspective must be tried and tested and accepted on a societal level. In kinships, stabilised expectations towards others are developed in intimate relations, and these expectations towards others will last irrespective of tensions and challenges. The intimacy pervading kinship-internal expectations provide social connections with clear action patterns and identity roles. Generational belonging in kinships denotes expectations in interaction that reflect their roles as child, parent, or grandparent. Among the kin's members, stable expectations to other members are related to familiar background knowledge and shared moral approval of how to live life and are developed and acted upon only relevant to the kinship in question (Habermas, 1996a).

Processes of modernisation all pull away from traditionalistic and kinshipbased social orders. Well-known processes are labour differentiation, the epistemic disenchantment of shared knowledge and meaning, increased social complexity, and reasonable pluralism (Eisenstadt, 1971; Giddens, 1990). Modernisation is nevertheless not occurring in a vacuum but is pulled by the social system itself, and most often, there is a type of mutuality of expectations that makes it possible, namely a shared agreement that stipulates that a particular developmental path is desirable. Through shared respect of religious authority or metaphysical worldviews, what once kept societies together has gradually been pushed aside from their dominance and replaced with alternative ways to establish social order. What is implied is a shared composition of norms that generate general solidarity within the social system and maintain order (Rehg, 1994).

\section{Motivation towards order across generations}

The second step is to explain the motivating force of individuals to orient themselves towards social order as a conflict-free network of individuals bent on interacting collectively. To do this, we can invoke the well-known situation of double contingency. This is a hypothetical experiment in theoretical sociology replicating the so-called Hobbesian problem of order. Talcott Parsons designed the problem to capture a challenge to sociology on explaining the emergence of 
social order from within a situation of uncertainty, danger, and disorder, something that Thomas Hobbes does in Leviathan (Parsons, 1951a). To Parsons and the Hobbesian problem of order, individuals who are motivated only by rational self-interest seemingly can establish the social order we currently live in. In contrast, social order depends on a predictable adherence of individuals to social norms that need to be genuinely understood collectively and understood similarly from one person to the next.

In the situation of double contingency, both individuals' actions are conditioned by how the other acts. How should they act to solve the problem of order, to deal with existing contingencies, where insecurity is caused by the uncertainty of action choices of the other? If you do not know who the other person is, it can constitute a danger to engage, and the rational thing to do is not engage. The only thing you do know is that the other person is also most likely driven by selfinterest. How can they generate expectations towards each other that make interaction safe and predictable, eventually leading to order? What makes your peer lower their guard and begin to trust and cooperate to create and coexist within a societal order?

In its basic form, double contingency consists of two individuals engaged in interaction for the first time. At this time, they have no reason to trust one another, leaving order too big of a risk to take provided individual self-interest is the only action-norm available to those involved. If more individuals engage, the contingencies increase exponentially. To Parsons, the establishment and prevalence of order demanded an additional element that is not reducible to rational selfinterest and can establish order. He referred to it as a typical "value-orientation" and public accountability mechanism in action choice (Parsons, 1968). However, Habermas goes beyond value-orientation while attacking Parsons" lack of "cognitive procedures and theory of meaning" and locates the solution to the problem in the development of language itself. Within the notion of public accountability, Habermas argues, lie both the need for and a key purpose of communication. Through the properties of communication, individual agents carry the cognitive resources to solve the problem of order. To Habermas, language internalises and normatively binds individuals in interaction (Habermas, 1987). As individual agents must trust others during interaction, language provides individuals to be communicatively motivated to coordinate action through mutual understanding.

If those engaged want to have a solution to the problem of order, a regular answer, and which depends on the potential within language, is to learn and know what to expect of others by way of interaction (Baier, 1986; Luhmann, 1979). This is another way of arguing that social order presupposes individual members motivated for interaction through stable behavioural expectations developed through mutual understanding (Habermas, 1987). Developing workable expectations that individuals can act on can thus incrementally establish and expand the number of workable expectations, i.e. those expectations that become confirmed through interaction, and expand social order. Expectations utilised to handle the dangers of contingencies will depend on the normative character of the motivating force of interacting agents within the order and how they have established mutual 
understanding regarding what action norms are legitimate and what to expect of others.

Within social order, the expectations that keep order are normative, fallible, and in constant fluctuation. To Parsons, as we also invoke here, individuals become socialised into carrying a disposition towards acting on shared behavioural expectations and becomes the culture the specific individual belongs to (Heath, 2001). As social order prevails through time, we can begin to understand that the changing character of norms is a change among those that carry them and constitute social order. Perhaps the difference is not significant from one year to the next, but ten years apart, then we can expect a variation of how norms are conceived, their substantial meaning, what norms correspond to what expectations, and so on.

This is how social order can be, it is argued, carried through time by concurrent social generations. Depending on specific social generations, i.e. specific birth cohorts, we can locate what norms can be argued are internalised and contribute to order and maintain order through time. Hence, each social generation carries their version of social order, whereas the complete order can merely be understood by studying all generations simultaneously alive.

Changes in norms express a cross-section of concurrent generations, where successive birth cohorts simultaneously express their conception of mutual understanding. In this scenario, multiple sources of friction among generations can occur. Still, most have to do with how mutual understanding is conceived and how each generation paddles their interests in a scenario where they need to establish mutual understanding with others.

\section{Mutual understanding and solidarity}

The components needed to explain order, and how norms develop and how a nexus of expectations is built that individuals apply during interaction belong to the broader and more general discussions on social interaction. Here we will focus on how individuals interact through basic communication to explain social order by having individuals motivated towards mutual understanding and solidarity to avoid disorder, danger, and a "brutish and short" life. Expectations that individuals carry can be directed towards generally applied action norms where one can expect that others choose to act upon certain action norms instead of other norms.

Expectations gradually become settled through interacting individuals seeking out mutual understanding, despite contingencies, to continuously secure social integration of order (Habermas, 1998). The expectations become tacitly embedded in order, carried by individuals across concurrent generations, and continuously applied. The nexus of expectations simultaneously also express a settled mutual understanding that becomes a normative expression of order that is general solidarity (Rehg, 1994). As interaction proceeds throughout a social system, the defining characteristics of viable expectations are observed to be used by interacting individuals. We can thereby observe social generations and how they act upon, conceive, and respond to age-sensitive expectations, i.e. expectations they apply because of where they are in life. Once expectations express 
mutuality, agreement, or even overlapping interests, they can become intersubjectively applied through interaction and used to anticipate others' behaviour. Mutual understanding of expectations is a stable and intersubjective concept of affirmed mutual behavioural patterns among interacting agents (Habermas, 1996a, 1998).

When interacting agents apply expectations, they are directed towards specific action norms that individuals may choose from "as temporally, socially, and substantively generalised behavioural expectations" (Habermas, 1996a). Expectations are thereby considered a basic component to action norms and become revealed once norms have become articulated. You interact by following what a specific action norm prescribes; we simultaneously claim to act upon expectations others have towards your action. Expectations thereby carry a shared and stable set of norms maintained and acted upon through mutual understanding among interacting agents. On the greater scale of social order, valid norms consist empirically of those action norms that have been passed down through history and that have been found acceptable and continuously acted upon because it is expected and because you expect it from others.

In this learning process, generations play a significant role, and by analysis of social generations, we can unveil the nexus of expectations, both as social generations and as concurrent generations. Birth cohorts always have a shared temporal event horizon. From a welfare state perspective, each individual from a specific birth year run through their lives, becoming confronted by the same type of welfare state regulation. When you view each birth cohort that overlaps one given year, each social generation has a different event horizon compared to where in life you are. In 2021, a person born in 1945, a person born in 1975, and a person born in 2005, all simultaneously become affected by the welfare state, but from different perspectives. They are motivated differently towards reaching mutual understanding; they also carry with them norms to act upon due to where they are in life. Each generation shares certain necessary contingencies that they bring with them into the process of affirming and reaffirming order. So mutual understanding constantly is in fluctuation due to how social generations, as a significant organising mechanism to social order, engage in interaction.

If a social system has established order, we can assume that a sufficient number of norms have reached the status of mutual understanding, so a relatively stable interaction can proceed. Those norms that guide actions take on a moral significance, and the social system becomes more dense. With a corresponding density of norms reached by mutual understanding, the more morally significant the social system becomes for the individual harbouring it. This is what will be referred to as general solidarity; and the higher the degree of individual conformity to solidarity, the more stable and socially integrated the social order. The higher the intersubjective orientation towards a common normative value set within a social order, the more the solidarity becomes embedded.

General solidarity emerges and is reaffirmed as a continuous and reflexive outcome from interaction (Rehg, 1994). It is also a multi-level concept. The first level alludes to solidarity related to mechanisms of social interaction that can establish social order. The second indicates the specific normative versions of solidarity that 
a given social order provides. Hence, the first level is fundamental and treats solidarity as part of the human potential for living social lives. It is both a motivating force for interaction and ensures social integration of social order. In this way, the concept of solidarity is interlinked with the ability to create mutual understanding among peers within the social system, ensuring that they are motivated to become more integrated. Solidarity becomes the outcome of "joint involvement" across social networks, social relations, and social interaction (Habermas, 2015). In the situation referred to as double contingency, upon interaction, A and B both carry expectations towards the other, and also action norms that can answer the expectations in a manner the other can agree to (Habermas, 1987, 1992; Parsons, 1951b). The "joint involvement" settles that A has demanding expectations towards B's actions. B is confident that A will behave reciprocally in the future if needed towards the choice of action that B takes. Then, on an analytical level, individual actor A or B's action norms become intersubjectively harmonised as the interaction proceeds. By elaborating on this level of solidarity, we can also unravel that certain interaction types can have a disintegrative effect on solidarity. This is especially so if breaches in mutual understanding become observed and that once again contingencies become visible, danger arises, and you no longer know what to expect of others. The mechanisms underpinning how social order is established is a precondition for general solidarity. By studying shared norms, we can unravel how the mechanism operates to produce solidarity in the first place, not only the combination of premises needed to explain how mutual understanding is built but also the motivation to act upon mutual understanding.

The second level of solidarity is parasitic upon the first level, and combined, they will be referred to as general solidarity. Here, solidarity is the normative expression that the norms take and which interacting agents have mutually agreed to. Solidarity on this level serves the dynamic function of bridging the individual's ethical decision-making on one side to that of norms carried by all individuals constitutive of social order, on the other. It is the material normativity of personal motivation for joint involvement. If a claim upon action reaches the mutual understanding, its corresponding action norm can become incorporated into the social order and become a motivation for joint involvement in interaction. In this way, each individual's ethical enterprise, in the sense of how that person wants to live life, becomes separate from but simultaneously encapsulated by the acceptability of the normative order of the social order (Habermas, 1996a; Rawls, 1971).

Whenever breaches of mutual understanding occur on the first level, or whenever participants disregard the moral imperatives of solidarity on the second, however minor it is, tensions arise, and the character of social bonds begin to disintegrate. Typically, this is a necessary dynamic for the re-production, re-integration, and affirmation of solidarity and is a motor for change.

The second level of solidarity can even be distinguished into more types of solidarities, depending on the roles norms have to certain sub-groups of the social system itself (Rehg, 1994). For instance, take social generation as a point of departure. A specific generation can carry a specific solidarity that a birth cohort adheres to as they go through life. Furthermore, concurrent generations at 
a certain time can be dubbed as a current solidarity as it is the general solidarity at a particular time.

Social order becomes a platform of shared expectations among individuals and social generations that originate and develop according to efforts of forming mutual understanding upon what action norms to choose from among interacting agents. If this platform shakes, i.e. that we no longer can expect others to act upon shared action norms, one becomes...

... confronted by the alternatives of switching to strategic action, breaking off communication altogether, or recommencing action oriented towards reaching understanding at a different level, the level of argumentative speech.

(Habermas, 1999, p. 24)

If expectations towards others break down, we are again left with our rational selfinterest, in a situation of contingencies, and motivation towards mutual understanding regarding expectations must develop anew.

In a complex world, it has become a truism that each actor become interdependent in order to get by. Thus, the number of situations characterised by contingency has increased (Luhmann, 1979). A modern society even presents hidden contingency, in that there are many aspects of an individual agent's life that the agent is unaware that it depends upon. This holds especially in modern complex societies, where social order is built upon mutual understanding that you cannot be a part of. The potential of successes or failures of others, known or unknown, whom we interact with and that affect us are crucial for many outcomes in our daily lives.

\section{Generation-specific norms}

Here we are preoccupied with double contingency situations and how contingency compels us to establish mutual understanding concerning action norms to establish social order among concurrent generations. If some of these four rules become violated, mutual understanding regarding what action norms to proceed with, and ultimately the composition of solidarity, will not have a solid foundation. Disagreement will make intergenerational contingencies visible, and actioncoordination again will become challenging due to disorder.

Intersubjective and stable action norms cannot be maintained if what is correspondingly expected does not apply any longer. So the interconnection between expectations and social norms is imperative for the order to prevail. If what is expected, for instance, between conjoined social generations no longer applies, then the social order must become revised. The only way to re-establish order is to discursively involve anyone who must abide by the action norms that are to be agreed upon - those who collectively constitute the order - and once again establish mutual understanding. If not, action norms would not be established upon a mutual understanding, and there would be no incentive for others to act upon them; coincidentally, nobody would know what to expect, and order would not be established. 
Including everyone affected by the action norm in the process of argumentation is equivalent to instilling accountability of the outcome of that particular communication upon all participants. Each participant, irrespective of generational belonging, must expect that everyone affected by the action norm could raise a claim to test its validity, all in the effort to secure that an action norm is reached through mutual understanding. If action norms are to establish order, false and weak expectations must be eradicated and replaced by general expectations achieved through mutual understanding. Action norms aim to generate order and have a coordinating effect through mutual understanding of what interacting agents will be likely to do, want, and act upon in the future.

Mutual understanding concerning action norms is a coordinating mechanism in interaction, and basic to the coordinating effect of mutual understanding is confirmed expectations and that norms are acted upon. Mutual understanding that validates action norms also let interacting agents know what to expect from one another. Order can thus be established by way of the coordinating effect that expectations provide in interaction.

The aim of reaching understanding (Verständigung) is to bring about an agreement (Einverständnis) that terminates in the intersubjective mutuality of reciprocal comprehension, shared knowledge, mutual trust, and accord with one another.

(Habermas, 1999, p. 23)

Social order is not established by mutual understanding alone but from the expectations established towards the action norms others choose to live by. It is by these actions that mutual understanding becomes reached and confirmed.

As participants representing social generations enter this discursive environment, knowing it involves raising criticisable validity claims, each participant of a social generation becomes obligated to follow the outcome due to the illocutionary force carried by a mutual understanding. Each participant of any social generation should accept the outcome as participants in discourse and develop as part of the normative composition of intergenerational solidarity. The participants in discourse bind themselves in the presence of all to take the propositional content of the accepted action norm into account in how they subsequently interact. This illocutionary obligation is a consequence of participating in validating action norms. It is an "obligation relevant to the sequel of interaction ... inasmuch as it establishes between speaker and hearer an interpersonal relation that is effective for coordination" (Habermas, 1984, p. 296). Hence, validating action norms, needed for action coordination, depends upon the illocutionary force of speech acts. By reaching mutual understanding of action norms, expectations can be shaped and applied during interaction to create order.

To sum up, in search of mutual understanding, individuals within social generations assume that each generation will argue their self-interests. The resulting agreement, among concurrent generations, will stand as the valid action norm for further interaction until a conflicting but reasonable valid claim is raised and 
creates tension. Social integration of this kind is driven forth by the "illocutionary binding energies ... to reach understanding" and makes solidarity imperative as you can expect others to act predictably (Habermas, 1996a). If a new assertion enters public discourse, its claim can shake and replace former agreements and establish new norms that again feed into the social order. In this manner, unknown expectations can develop within order. This dynamic is not necessarily ensuring a "better" direction. No matter what the binding force of solidarity may look like, social order is an empirical set of norms that members of the social order subscribe to.

\section{Pluralism and complexity as key source of tensions}

Social orders are constantly in flux. As social order responds to individuals seeking to coexist and solve problems together, and as social generations are introduced and take part in order, they also bring with them new concepts and interests that ultimately change the composition of order and the character of solidarity. Social generations can thereby bring specific tensions that influence how concurrent generations shape mutual understanding. Established action norms can be challenged and cause questioning whether or not expectations can be applied accurately or if formarly workable expectations need to be thrown out of what constitutes order altogether. To illustrate the effect of tension, younger social generations can have specific needs and interests that older generations do not have and which the younger generations seek to embed into a welfare state. Or, if democratic law-making has managed to stabilise social order into the legal order, tension within social order can spill over to cause a legal order not to respond adequately. There are especially two main traits with modern complex liberal democracies that cause tension to and within order: (1) reasonable pluralism and (2) increased societal complexity, and especially through work and epistemic differentiation.

Reasonable pluralism, first, deals with the consequence of liberal societies granting liberty rights to each citizen to act upon and choose a way of life, a lifestyle. This leads to reasonable pluralism of world views (Rawls, 1993), and within welfare democracies, it "is the normal result of its culture of free institutions" (Rawls, 1997). The establishment of constitutional protection of individual liberty thus becomes a hallmark of "free institutions". Reasonable pluralism also shapes social generations where birth cohorts travel through time and become offered opportunity sets they can act upon relevant to their position in time. How reasonable pluralism worked 20 years ago is not similar to how it works today. Only the share magnitude of reasonable choices on how to live life has grown, but many also fall out, for instance, due to technologies that are phased out, leaving certain lifestyles and work places out of reach. The climate crisis is one example that we can expect that certain ways of life become phased out. Equally, the gradual realisation of and the implementation of reasonable pluralism has rationalised and intellectualised earlier common religious or sacred worldviews and left them fragmented. In Weberian terms, 
the disenchantment of the world has left it open for individuals to strive for whatever reasonable conception of good they might choose (Weber, 2004), and which do not violate an equal distribution of such a choice, which ensures others also can choose their conception of the good. The gradual disenchantment ethically neutralises societal order to the degree that it can encompass different reasonable worldviews. The process has been a hallmark of transition from traditional to post-traditional societies and liberated successive generation as time goes by.

Since individuals can choose how to live life, different possible choices will vary continuously according to what individuals want out of life. It will lend pressure to those action norms that have previously been agreed upon. Certain action norms will diminish, contested and reconsidered, while new norms can begin to take shape that one day could receive general recognition. In such a manner, reasonable pluralism will constantly challenge the existing set of action norms and the behavioural expectations associated with the action norms. The fact of reasonable pluralism still provides tension to order (Rawls, 1993).

The second is about collective problem-solving and coordination through the steady growth of societal complexity. Modernisation processes ensure the differentiation of functional subsystems that also reproduce themselves (Bohman, 1996; McCarthy, 1985). As each of these reproduces themselves, they differentiate into further subsystems that simultaneously also intersect across functions. Examples of such spheres are economy, educational systems, and organisation of politics (Luhmann, 1979). For instance, how social generations are left with options to participate in a market economy relative to access to resources and demand leaves a current marketplace responding to generational shifts. Also, the educational systems are set to reproduce and reinvent social norms as those educated further develop and reinvent education corresponding to new knowledge and new technologies.

The increase in complexity shares with the increasing variety in reasonable pluralism a growth in the number and type of reasonable action norms individuals can choose from and what needs they have, and what interests they possess. In this respect, it is a steady growth in the number of general expectations within an order, which leaves pluralism and increased complexity as key to understanding how tensions arise.

\section{The welfare state and political solidarity}

The need to achieve and make valid claims across many types of value spheres facilitates the logic of communicative rationality and the need to reach a mutual understanding that can lead to, and become, crafted into a legal order of a welfare state.

Modern law can stabilise behavioural expectations in a complex society with structurally differentiated lifeworlds and functionally independent subsystems only if law, as regent for a "societal community" that has transformed 
itself into civil society, can maintain the inherited claim to solidarity in the abstract form of an acceptable claim to legitimacy.

(Habermas, 1996a)

Expectations can become stabilised by embedding them as rules in a legal order, and from where they become reference points on what to expect from the welfare state itself. Each citizen becomes able to hold the legal order as a reference point for what to expect from the welfare state and from others. Hence, a legal order can be referred to as having the ability to stabilise the social order's general expectations into legislation, regulation, policies, and welfare programmes. We can thereby argue that the solidarity within the social order can become enacted as legislation as political solidarity responds to the social order's actual solidarity.

For the legal order to have this potential, it must be established through a lawmaking procedure that includes the vindication of claims raised through legalpolitical discourses that include all those constitutive of social order (Habermas, 1998). As public deliberation commences, citizens can raise claims that combined can express the needs and interests specific to social generations in their capacity as members of a social generation. If a legal order is crafted that reflects solidarity within the social order, it can be argued that the legal order is stable and expresses concurrent democratic agreements of what action norms one can expect others to abide by.

As a result of modernisation processes, the variety of action norms within a social system has become insurmountable. This holds true even for the welfare state's organisation and how politics has developed such a state to serve any individual's needs throughout history. Nevertheless, social generations represent individuals of the same age that meet challenges simultaneously and thereby carry certain interests collectively. For instance, the need for kindergartens, high-quality public schools, age-related health care, retirement benefits, etc.

A welfare state is one way or the other embedded into a legal order, and it is activated as individual citizens raise a claim on satisfying needs or interests as a matter of right (Goodin, 1986, 1988). They carry rights to different benefits (e.g. unemployment or disability), education, in-kind assistance, and so on. However, a welfare state is set to secure a decent level of wellbeing for each citizen, no matter where in life that individual is. Hence, depending on what social generation you are, certain specific benefits are made for you and not others. As you travel through life, you have certain rights as a child that you lose as adulthood ticks in and so on. However, as the welfare state is stabilised through legal rules, it would provide for the same type of interests and needs, and through the same type of rights, forever. Hence, the democratic ethos of self-government calls for amending how the welfare state addresses the ever-fluctuating needs and interests of generations that come.

A welfare state, embedded in a legal order, brings out the internal and necessary tension between the legal- and social order. One de facto general solidarity is embedded in the social order, while another de jure solidarity is stabilised into law. Once general solidarity within the social order fluctuates, it creates tension 
to the normative order stabilised into law, i.e. a tension between general solidarity within the social order to political solidarity (Habermas, 1998; Rehg, 1994). The tension alludes to the dynamics of democratic politics to resolve tensions by addressing social change and making welfare state provisions more accurately targeted to generations' needs and interests. The rule of law and the potential disintegration between the positivized welfare state structure of the legal order, and the character of solidarity of the social order, calls for changes to the political order. Since social order is continuously in flux, the welfare state is expected for must change as a legal order can only replicate social solidarity into political solidarity at a particular moment in time and stabilise one particular version of it at the time (Habermas, 1996a).

When there is no tension between the legal order and the social order, it can be argued that the social order and the solidarity it carries are also embedded in the legal order as political solidarity (Banting \& Kymlicka, 2017). This is very hard to achieve perfectly due to fluctuation. Still, welfare state democracies carry a legal form with the potential for a driving thrust to stabilise expectations residing in social order into the legal order through political craftsmanship. Consequently, tension arises from the fact that solidarity within the social order always can become stabilised norms embedded in the legal order. As the legal order stabilises expectations at one moment in time, the social order develops away from what was once stabilised. Being politically vigilant and upholding a claim on the democratic legitimacy of the welfare state, the social order requires a commitment to incorporate behavioural expectations within the social order continuously and correctly into the legal order or dissolve those legal norms that are wrong. Accordingly, it is a matter of political craftsmanship to what extent solidarity is embedded in the welfare state and whose specific solidarities are given priorities and how.

Across generations, we can argue that whenever legislation is set to organise, maintain, and enforce work inclusion that was made 20 years ago, new social generations have other work types to go to; they have different educational backgrounds, thus carrying new types of expectations to what the welfare state is set to do. Incorporating new expectations into the legal order can push the legal order once again in the direction of being in line with solidarity or merely adjusting legislation to fit the specific solidarity of any given social generation. However, an unavoidable consequence of having ruling majorities, with certain generations due to how the system is set up, in charge, the complete general solidarity of the social order will never become embedded all at once into a legal order. It will always be imperfections and tension and a need for political craftsmanship.

\section{The dynamics of political craftsmanship}

Democratic rule of law implies some version of the Rousseauan civic republican liberty bestowed on each to partake in self-government (Habermas, 1998; Rawls, 1993). A hallmark is that concurrent generations simultaneously engage in public discourse revolving around their self-interests and needs. 
Tension can arise between how to prioritise among generations' needs and interests through designing new legislation, regulation, policy, and streetlevel practice, which constitutes the legal order, on the one hand, and match the basic and current solidarity of the prevailing social, order on the other (Habermas, 1996b). Since the social order in itself can become stabilised into law by way of answering the behavioural expectations of individuals in their capacity as a member of a generation, it becomes possible to approximate the social order by studying the political-legal discourses on the welfare state's legal development, and how interests and needs are mitigated and answered within the welfare state scheme.

At any point in time, the social order can be studied through the lens of democratically forged law assumed to be genuinely democratic. A legal code from 2009 can be said to be the attempt to stabilise an order constitutive of concurrent generations in 2009, and this can be compared to, for instance, 2004 or 1994. However, as time progresses and new generations begin to shape expectations towards others, new societal norms that seem insignificant in the past can become dominant in a future order. For instance, social generations born after 2010 will have a completely different view on how public service operates technologically. There is perhaps no need for social service offices like earlier, and perhaps hospitals become more mobile. Hence, erupting from the facticity of different social generations within the social system itself, new expectations can, as already argued, penetrate, develop, and put legitimate pressure on the legal order from the outside and change how it works, and thereby change how the welfare state works. Thus, tension arises between solidarity, on the one hand, and the type of solidarity that is settled within the legal order, on the other. As democratic welfare states are concerned, tensions must be alleviated to avoid escalation into conflict. Hence, political craftsmanship must stay vigilant to ensure that the legal order stays aligned with the solidarity the social order prescribes and the respective current solidarities that push themselves through everyday politics. Order will develop and be different in 1992 from what it was in 1982, and if the legal order has not changed with it, democratic law-making does not follow. If, for instance, a ruling class also is conjoined social generations, and reaping the benefits of certain welfare state benefits, it undermines the principle of popular sovereignty, set to provide each social generation relatively equal representation to its share number of individuals.

Once each individual is constitutionally inserted as a citizen into the democratic procedure of law-making, a welfare state can be designed to answer each individual's needs and interests according to their rational self-interest (Habermas, 1996a). This implies that certain birth cohorts will have certain needs other birth cohorts do not need, such as pensions or kindergartens or education. Although certain solidarities in this manner can be specific to certain social generations and vary through time, a formal principle of justice that upholds each person's right to partake in self-government implies that individuals, across generations, also have a right to have their interests and needs met equally (Goodin, 1988; Shapiro, 1999). 


\section{Conclusion}

To explain the prevalence of a welfare state, one that can withstand tensions and conflicts, a concept of generation must explain social integration processes that develop, affirm, and continuously reaffirm a level of solidarity to be operative in the welfare state itself and to ensure system integrity, supportive of a welfare state, across time. What is implied is a certain level of social integration and trust to be observed within and among generations at a specific cross-section in time in a social order. Individuals of different birth cohorts willingly internalise and act upon shared social norms as a matter of solidarity. Solidarity in this vein becomes the denomination of normative thrust that belongs to society's background consensus (Rehg, 1994).

It is possible to view the ideal type of the democratic welfare state as a political expression of the normative self-understanding of solidarity that permeates a particular community's social order. This occurs, ideally, as the composition of the popular sovereignty within the realm of social order becomes perfectly aligned to the political scheme of redistribution within the welfare state. To reach such an aim, democratic politics and law-making draw upon those action norms that dominate and stabilise them into the welfare state construct.

In such a scheme, generations play an imperative role as the operative expression of the different entries of engagement a welfare state has throughout the lifecourse. To each social generation, constituted by citizens of the welfare state, the welfare state addresses them universally according to a principle of equality. An advanced welfare state democracy thereby can establish a welfare state system that draws on social solidarity within the social order to develop a stable system of political solidarity. When the two solidarities are in harmony, we can argue that the welfare state system delivers on what is expected from across generations. Hence, expectations towards the welfare system emanate within a social order, directed at the political order. The tension becomes a denomination of the distance between what is expected and what is delivered.

If, on the other hand, there is a discrepancy between what a social generation expects and what the welfare state delivers, tensions arise. These can be everything from trivial tensions to conflicts and crises. However, when we apply a generational perspective that has the birth cohorts as a point of departure, it becomes imperative to view the tensions that arise from the social generation's perspective if specific cohorts are more in tension with the welfare state than others. Concurrent social generations can have different relations towards the welfare state, some generations potentially experience more harmony between social and political solidarity than others.

A constitutional democracy, with a welfare state embedded into it, passes through history as each generation of citizens continues to pursue and reaffirm its normative intent to uphold social solidarity, continuously overcoming tensions that contest the pillars of the welfare state. Although the organisational expression of the welfare state changes in character and responds to the population's needs, a fundamental set of redistribution norms, as a temporally delimited conception of 
solidarity, prevail across generations. As a welfare state lasts across generations, it cannot be claimed to be the need for a redistribution scheme at a cross-section in time. The agreement across generations stands as imperative as reflecting the social order itself and what people want.

\section{References}

Aboim, S., \& Vasconcelos, P. (2014). From political to social generations: A critical reappraisal of Mannheim's classical approach. European Journal of Social Theory, 17(2), 165-183.

Baier, A. C. (1986). Trust and antitrust. Ethics, 96(2), 231-260.

Banting, K., \& Kymlicka, W. (2017). The strains of commitment: The political sources of solidarity in diverse societies. Oxford University Press.

Bohman, J. (1996). Public deliberation. Pluralism, complexity, and democracy. MIT Press.

Bristow, J. (2016). The sociology of generations: New directions and challenges. Springer.

Eisenstadt, S. N. (1971). From generation to generation: Age groups and social structure. Transaction Publishers.

Giddens, A. (1990). The consequences of modernity. Polity Press.

Giddens, A. (1991). Modernity and self-identity: Self and society in the late modern age. Polity Press.

Goodin, R. (1986). Welfare, rights and discretion. Oxford Journal of Legal Studies, 6(2), 232-261.

Goodin, R. (1988). Reasons for welfare: The political theory of the welfare state. Princeton University Press.

Habermas, J. (1984). The theory of communicative action. Reason and the rationalisation of society (Vol. I). Polity Press.

Habermas, J. (1987). The theory of communicative action. lifeworld and system: A critique of functionalist reason (Vol. 2). Polity Press.

Habermas, J. (1988). Legitimation crisis. Polity Press.

Habermas, J. (1992). Autonomy and solidarity: Interviews with Jürgen Habermas. Verso.

Habermas, J. (1996a). Between facts and norms. Contributions to a discourse theory of law and democracy. Cambridge, Massachusetts: The MIT Press.

Habermas, J. (1996b). Three normative models of democracy. In S. Benhabib (Ed.), Democracy and difference. Contesting the boundaries of the political. Princeton University Press.

Habermas, J. (1998). Inclusion of the other: Studies in political theory. The MIT Press, Cambridge, Massachusetts.

Habermas, J. (1999). On the pragmatics of communication. Polity Press.

Habermas, J. (2015). The lure of technocracy. Cambridge: John Wiley \& Sons.

Heath, J. (2001). Communicative action and rational choice. MIT Press.

Luhmann, N. (1979). Trust and power. London: John Wiley.

Mannheim, K. (1952). Essays on the sociology of knowledge. London: Routledge and Kegan Paul Ltd.

McCarthy, T. (1985). Complexity and democracy, or the seducements of systems theory. New German Critique, 35, 27-53.

Parsons, T. (1951a). The social system. London: Routledge \& Kegan Paul.

Parsons, T. (1951b). Toward a general theory of action. Harvard University Press. 
Parsons, T. (1968). The structure of social action. A study in social theory with special reference to a group of recent European writers. New York: McGraw Hill Book Co.

Pilcher, J. (1994). Mannheim's sociology of generations: An undervalued legacy. British Journal of sociology, 45, 481-495.

Purhonen, S. (2016). Generations on paper: Bourdieu and the critique of 'generationalism'. Social Science Information, 55(1), 94-114.

Rawls, J. (1971). A theory of justice. Boston: The Belknap Press of Harvard University Press.

Rawls, J. (1993). Political liberalism. Boston: Columbia University Press.

Rawls, J. (1997). Idea of Public Reason Revisited, The. U. Chi. L. Rev., 64, 765.

Rehg, W. (1994). Insight and solidarity: The discourse ethics of Jürgen Habermas (Vol. 1). Berkeley and Los Angeles, California: University of California Press.

Shapiro, I. (1999). Democratic justice. London: Yale University Press.

Weber, M. (2004). The vocation lectures: Science as a vocation, Politics as a vocation. Indianapolis, IN: Hackett Pub. 